American J. of Engineering and Applied Sciences 3 (1): 37-41, 2010

ISSN 1941-7020

(C) 2010 Science Publications

\title{
Seismic Response Evaluation of Moment Resistant Frame with Built-Up Column Section
}

\author{
${ }^{1}$ Mohammad Ebrahimi, ${ }^{2}$ Hesam Sharifian and ${ }^{2}$ Mohammad Ahangar \\ ${ }^{1}$ Faculty of Civil Engineering, Khajeh Nassir Toosi University of Technology, Tehran, Iran \\ ${ }^{2}$ School of Civil Engineering, University College Engineering, University of Tehran, Tehran, Iran
}

\begin{abstract}
Problem statement: Moment Resisting Frame (MRF) is widely used as lateral resisting systems when sufficient ductility and deformability are to be met. Response of these structures is strictly dependent upon behavior of their joints, whereas the analysis of steel moment resisting frames generally has been performed without considering the accurate connection behavior. Approach: In this study Finite Element (FE) models had been developed to obtain the moment-rotation relations of theoretically fixed connection types which were widely utilized in Iran. Using moment-rotation relation obtained from FE analysis, 2D global structural model of MR buildings were developed afterwards to evaluate the behavior of the structures globally. Nonlinear static and dynamic analyses were carried out subsequently to investigate the structural behavior of MRFs having built-up column sections. Results: The results proved considerable effects of beam column connection behavior on nonlinear response of structures. Conclusion/Recommendations: It was recommended to consider the effects of connection properties in analysis and design of the MRF.
\end{abstract}

Key words: Steel moment resisting frames, beam-column connection, energy dissipation, built-up section

\section{INTRODUCTION}

Steel Moment Resisting Frame is a structural system in which beam-column connections are made with fully restrained joints, thus allowing the flexural stiffness and flexural strength of the frame members to resist lateral loads. This system provides the structure with excellent ductility, making it ideal to be constructed in seismic active areas.

In the 1994 Northridge earthquake, however, early brittle fractures in beam-column connection areas occurred, causing significant damage. Thus, various American engineering institutions conducted experimental research on the behavior of steel moment connection and developing analytical modeling techniques and new design methods (Kim et al., 2002).

Commonly, In IRAN, the built up sections are constructed for columns and beams; however, relevant connection types exhibit different behavior comparing to connections made of box or $\mathrm{W}$ sections (Kim et al., 2006). Experimental research on inelastic behavior of these connections has not been conducted sufficiently; furthermore, proper analytical modeling techniques for the design purposes have not been appropriately developed to forecast their inelastic responses. Thus, this study tries to investigate the inelastic behavior of the built-up connection types.

\section{Existing analytical models:}

Linear centerline model: To design structures or evaluate the performance of existing buildings, there is a need to review two criteria, namely, strength of members and stiffness of the buildings. The linear elastic model using the central line model is suitable for designing a steel moment resisting frame. Although the model shows suitable results for design purposes, it cannot accurately forecast the distribution of the inelastic member forces induced by the dynamic load.

Elastic model with panel zone: Figure 1 shows the scissors model, which includes a panel zone. In this model, beams and columns are connected via rigid links in a panel zone and the crossroad hinge is connected via a spring with the stiffness of the panel zone. Since this model contains dimension and stiffness of the panel zone, it forecasts more accurately the distribution of shear forces, flexural moments and axial forces in comparison with first model.

Corresponding Author: Mohammad Ebrahimi, Khajeh Nassir Toosi University of Technology, P.O. Box 15875-4416, Vali Asr St., Mirdamad Blvd., Tehran, Iran Tel: +98-912-7374822 
Am. J. Engg. \& Applied Sci., 3 (1): 37-41, 2010

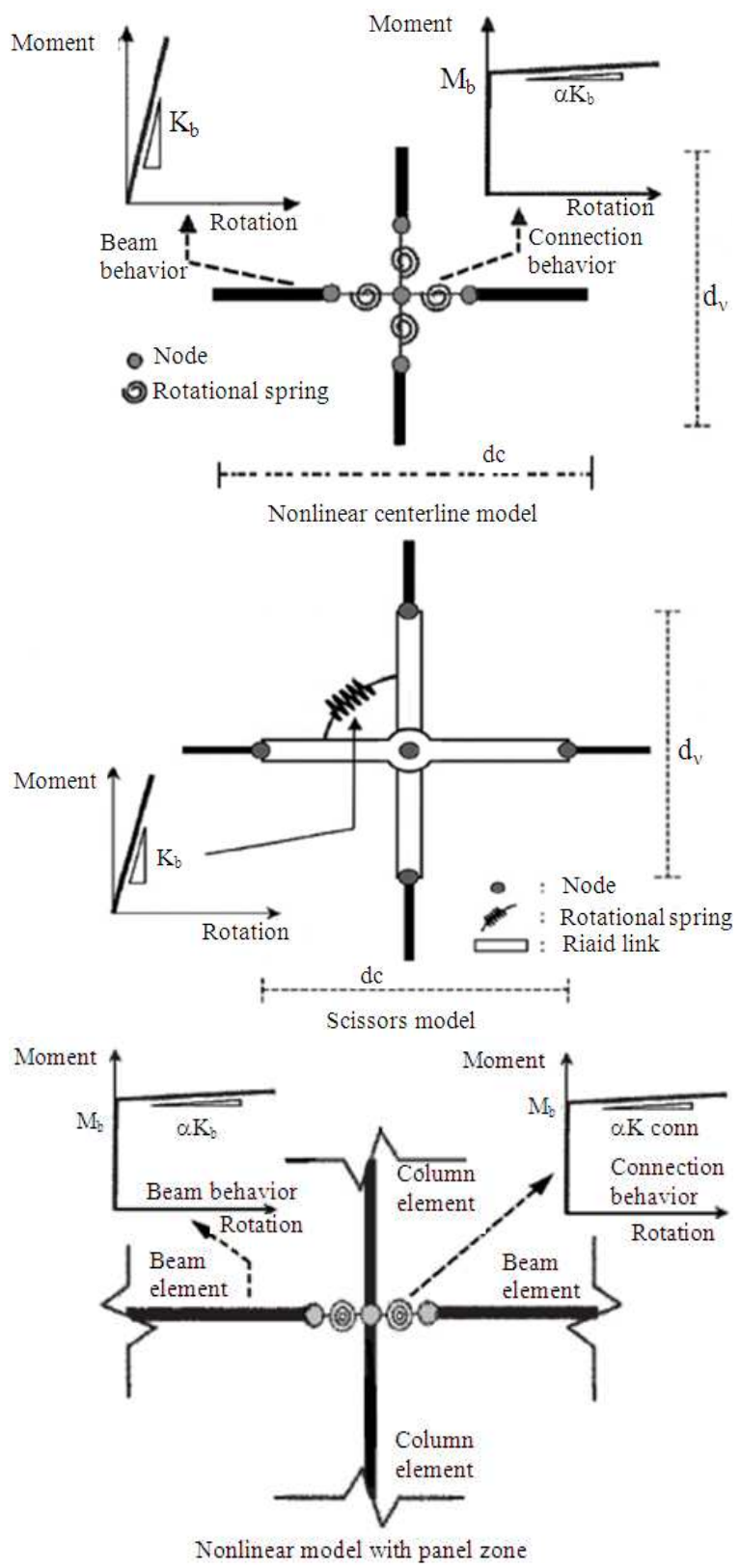

Fig. 1: Existing analytical models

Nonlinear centerline model: This nonlinear-inelastic model is also useful in assessing the behavior of existing buildings. To conduct nonlinear analysis, most commercial programs, as shown in Fig. 1, connect springs having nonlinear features with section properties of beams and columns.

Analytical modeling techniques for beam-column connections in steel frame structures are categorized as follows (Foutch and Yun, 2002).

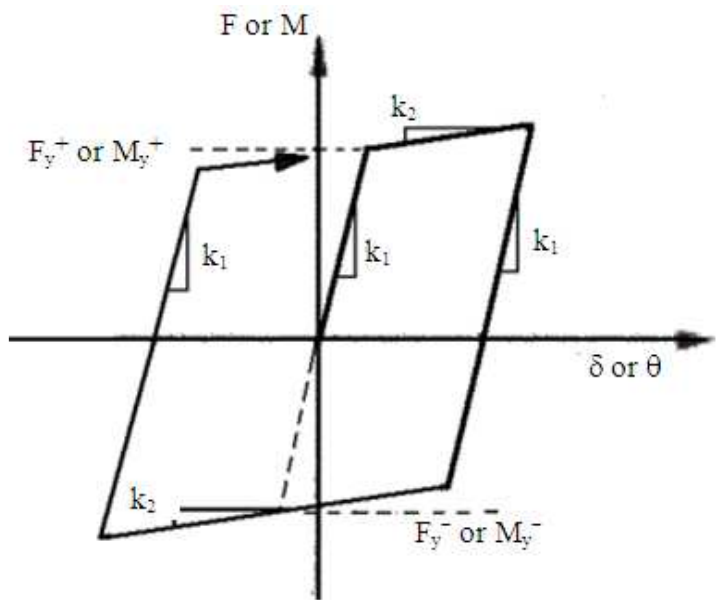

Fig. 2: Simple analytical modeling of the moment connection

Nonlinear model with panel zone: The nonlinear analytical models, which include panel zones, are categorized into three techniques. The first model is the scissors model in Fig. 1, containing nonlinear property for a spring element. The second one, shown in Fig. 1, uses two springs with panel zone's stiffness and the average strength of the panel zone and the beams. Although this model can express stiffness and strength of the panel zone, it cannot accurately express its shear deformation without expression of the accurate dimension of the panel zone. The third model developed by (Foutch and Yun, 2002; Krawinkler, 2000) models a panel zone into 8 rigid elements.

\section{Characteristics of analytical beam-column connection} elements: Previously, since a moment connection would be expected to show sufficiently ductile behavior, analysis would be carried out using the moment-rotation curve shown in Fig. 2. Since the 1994 Northridge earthquake caused early brittle fractures in the welded parts of moment connections. However, SAC Joint Venture has conducted experiments and research on moment connections (Kim et al., 2002). As such, it was observed that inelastic behavior in a moment connection was classified into: A yielding fracture in the welding area and reduced strength.

Accordingly, SAC developed the new beam connection ideal relations shown in Fig. 3 to model the performance of moment connections (FEMA 356, 2000). These moment-rotation diagrams characterize some major parameters which are initial stiffness, yielding rotation, maximum strength and ultimate rotation. 


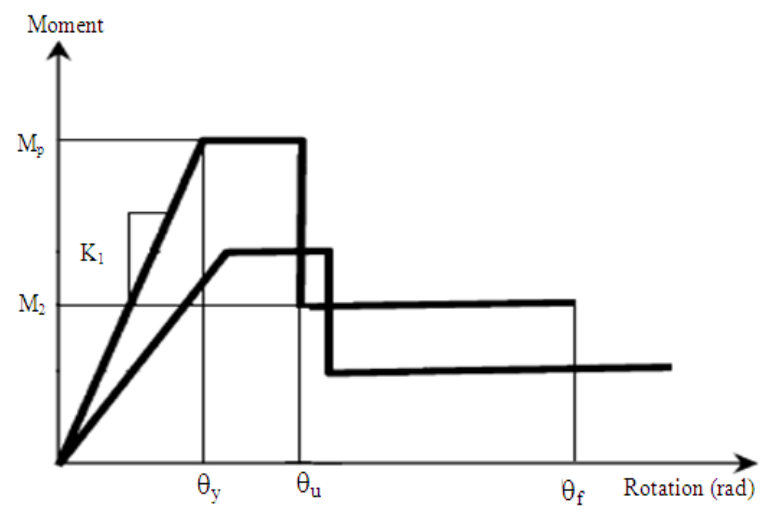

Fig. 3: SAC analytical modeling of the moment connection (ideal relation)

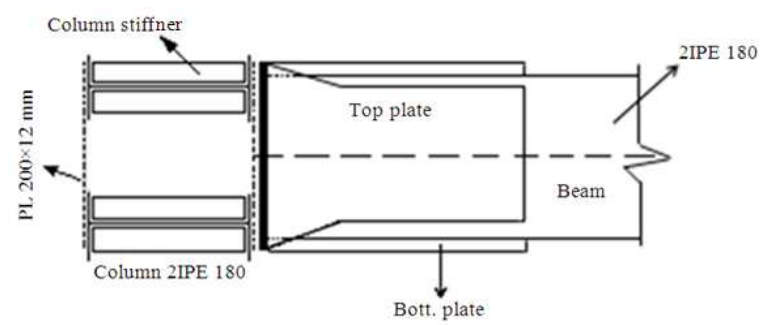

Fig. 4: Moment connection type of Iran

\section{MATERIALS AND METHODS}

Modeling and analysis: The moment connection types used in Iran are shown in Fig. 4. Finite element analyses under monotonic loading were performed to attain the moment-rotation curve.

First model is analogous to experimental model which utilized welded cover plate to column flange by plug (Fig. 1-5). The second model which is investigated in this study eliminates cover plate and use middle profile within two other columns at location of beamcolumn joint (Fig. 2-5). Properties of these connections are described in Table 1.

The result of finite element analysis (Von-misses stress distribution) is shown in Fig. 6. The momentrotation relations of the two connection types are provided in Fig. 7.

Degree of rigidity: Initial stiffness and rigidity are two of the most important factors which characterize connection behavior. When the rigidity was higher than $90 \%$, it is possible to assume that the connection is fully restrained (AISC, 2005). Thus second model which has rigidity equal to $96 \%$ has been classified as rigid connection while the rigidity of first model is almost $87 \%$.

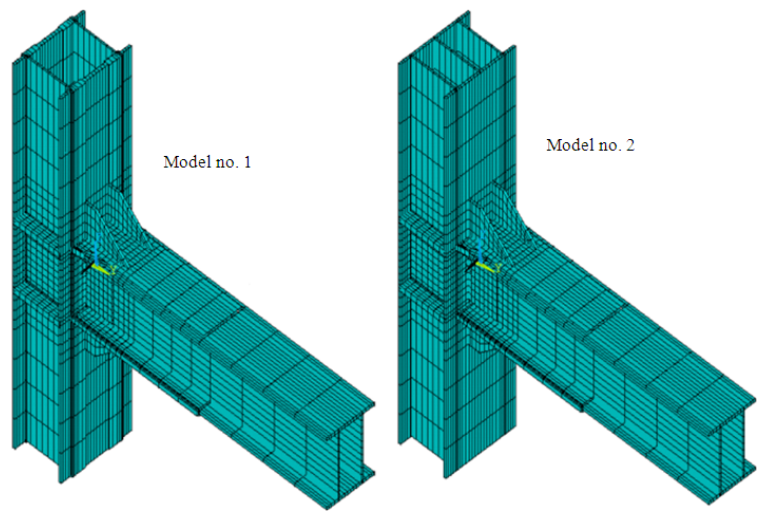

Fig. 5: FE model of moment connection types

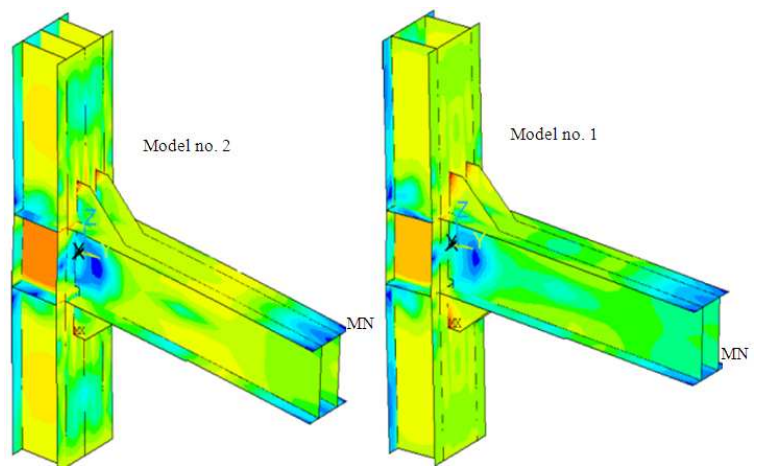

Fig. 6: Von-misses stress induced in connections

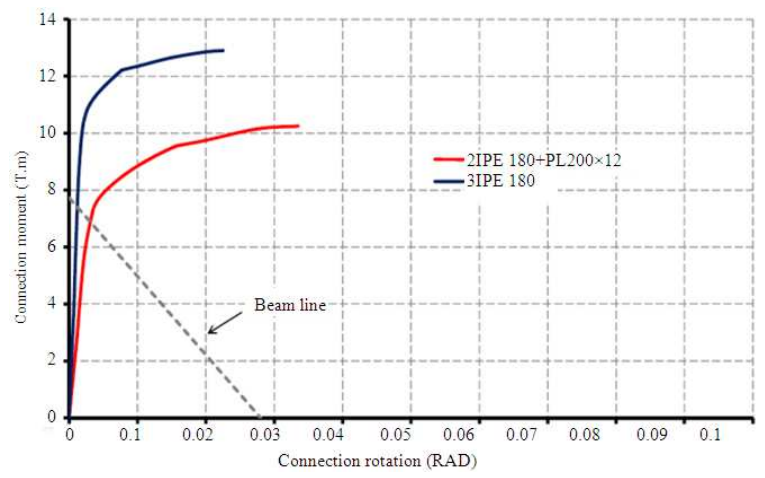

Fig. 7: Moment-rotation relationships of connection types

Table 1: Connection models properties

\begin{tabular}{lllll}
\hline $\begin{array}{l}\text { Model } \\
\text { no. }\end{array}$ & $\begin{array}{l}\text { Beam } \\
(\mathrm{sec})\end{array}$ & $\begin{array}{l}\text { Column } \\
(\mathrm{sec})\end{array}$ & $\begin{array}{l}\text { Top plate } \\
\text { dim. }(\mathrm{cm})\end{array}$ & $\begin{array}{l}\text { Bott. plate } \\
\text { dim. }(\mathrm{cm})\end{array}$ \\
\hline 1 & 2IPE180 & 2IPE180+PL200×12 & $50 \times 14 \times 1.2$ & $50 \times 20 \times 1.0$ \\
2 & 2IPE180 & 3IPE180 & $50 \times 15 \times 1.5$ & $50 \times 20 \times 1.2$ \\
\hline
\end{tabular}

Table 2: connection models capacities

\begin{tabular}{llll}
\hline $\begin{array}{l}\text { Model } \\
\text { no. }\end{array}$ & $\begin{array}{l}\text { Column } \\
(\mathrm{sec})\end{array}$ & $\begin{array}{l}\text { Yielding } \\
\text { rotation }(\mathrm{rad} .)\end{array}$ & $\begin{array}{l}\text { Ultimate rotation } \\
(\mathrm{rad})\end{array}$ \\
\hline 1 & 2IPE180+PL200×12 & 0.00275 & 0.0340 \\
2 & 3IPE180 & 0.00200 & 0.0225 \\
\hline
\end{tabular}


The yielding rotation $\left(\theta_{\mathrm{y}}\right)$, strength and ultimate rotation $\left(\theta_{\mathrm{u}}\right)$ of connection could be extracted from moment-rotation curve as shown in Table 2.

\section{RESULTS}

To evaluate the performance of buildings having these 2 connection types, two 5 story building model were analyzed. Fundamental periods of each model for the moment frames 1 and 2 are 1.39 and $1.31 \mathrm{sec}$ respectively. A rotational spring is introduced between the beam and column to model the beam-column connections. In this study, nonlinear finite element program OpenSees (Mazzoni and Mackenna, 1999) is used to investigate the behavior of the structure and its components.

Nonlinear static analysis: To conduct a nonlinear static analysis, the inverted triangle lateral load distribution has been applied on the structures. By using displacement-controlled pushover analysis, the effects of over-strength and P-delta could be observed.

As shown in Fig. 8, prior to fracture occurrence in the connections, two analytical models showed almost the same behavior. However, the stiffness of first model is lower than that of the second model; when the fracture is encountered in a connection, strength of the second model declined faster than that of the first model.

In evaluating ductility of the structure, the area enclosed by base shear-roof drift curve may be utilized. In case of the proposed model, the area beneath the base shear-roof drift curve was observed to deteriorate, which indicates lower energy absorption ability (Fig. 8). As such, connection fractures (connection capacity) have a marked impact on the behavior of moment resisting frames.

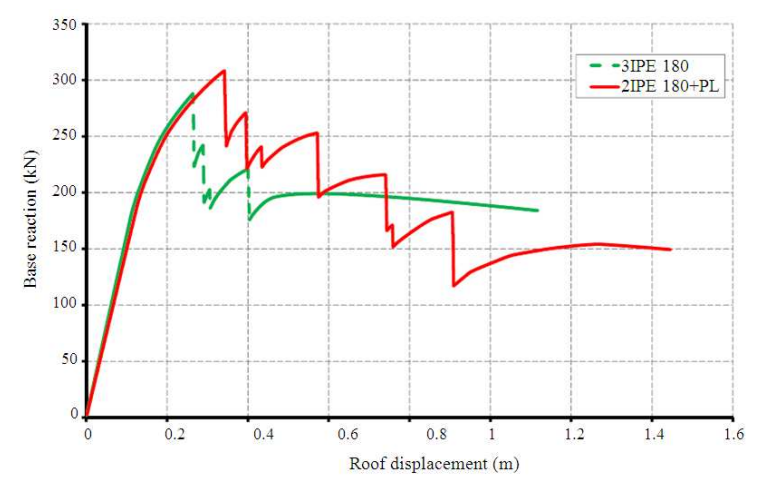

Fig. 8: Base shear and Roof drift of 2 MRFs
Nonlinear dynamic analysis: Nonlinear dynamic analyses were performed on the models to investigate the dynamic behavior of buildings having fracturing connection models.

As shown in Fig. 9, dynamic time history responses of the models are analogous at initial stages of the analysis. Sudden significant ground acceleration, however, caused fractures in the proposed model's connections (2nd) and thereby, a totally different time history from that of the first model was observed.

Energy dissipation is a mechanism by which a structural element (connection) does 'work' against the work done by input cyclic loads (earthquake). The amount of energy dissipation can be attained by means of calculating the area within the hysteresis loops. The sum of all enclosed areas within the loops provides cumulative hysteretic energy dissipation and it could be arguably assumed as a suitable measure to evaluate the efficiency of models performance. Comparative graphs showing the cumulative hysteretic energy dissipation for all models are given in Fig. 10. It is shown that model no.1 exhibits greater energy dissipation.

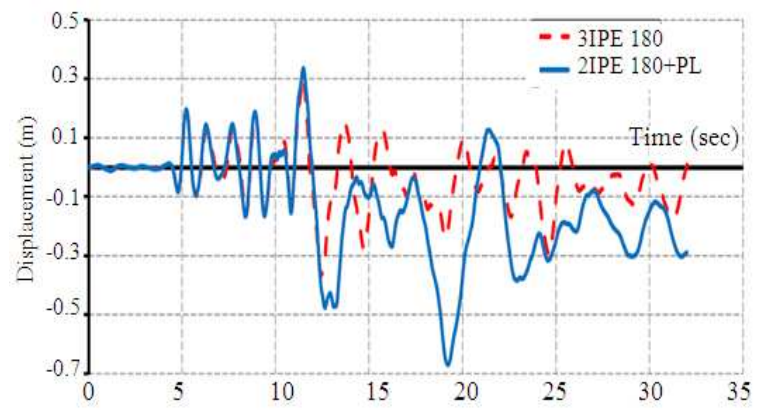

Fig. 9: Time history response of 2 MRF types

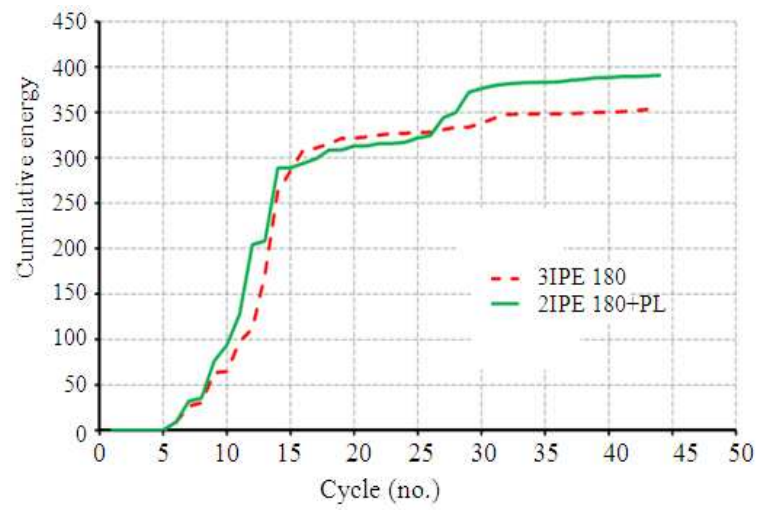

Fig. 10: Cumulative energy dissipation of 2 MRF types 


\section{DISCUSSION}

Built-up moment connections in steel moment resisting frames may not provide sufficient rigidity. Thereby, it is necessary to use special arrangements to increase rigidity of their connections. The proposed model increased degree of rigidity considerably.

\section{CONCLUSION}

This study by reviewed the commonly-used connection model in Iran and proposed a new model consistent with Iranian moment connections. Furthermore, to compare the behavior of the entire structural system, nonlinear static and dynamic analyses were performed. The following conclusions can be drawn:

- Iranian moment connections which designed based on Iran seismic Code provide sufficient ductility but inadequate rigidity. The special arrangement which was proposed in this study increased rigidity of connection appropriately

- To characterize the effects of Iranian moment connection on structural response; nonlinear static analyses of 5-story structure were conducted. There was strength deterioration in the proposed model after fracture occurred

- Moreover, nonlinear dynamic analyses were conducted. The energy absorption of the proposed model was almost $15 \%$ lower than that of the first model. One could select appropriate connection details based on design objectives

\section{REFERENCES}

AISC., 2005. Steel structure specification. http://www.aisc.org/WorkArea/showcontent.aspx?i $\mathrm{d}=17640$

FEMA 356, 2000. Prestandard and commentary for the seismic rehabilitation of buildings. http://www.fema.gov/library/viewRecord.do?id=1427

Foutch, D.A. and S.Y. Yun, 2002. Modeling of steel moment frame for seismic loads. J. Construct. Steel Res., 58: 529-564. DOI: 10.1016/S0143974X(01)00078-5
Kim, T., A.S. Whittaker, A.S.J. Gilani, V. Bertero and S.M. Takhirov, 2002. Cover plate and flange plate reinforced steel moment resisting connection. J. Struct. Eng., 128: 474-482. DOI: 10.1061/(ASCE)07339445(2002)128:4(474))

Kim, M.H., M.H. Oh and S.M. Kim, 2006. Analytical modeling and nonlinear analysis of beam-column connection in steel moment resisting frame. J. Asian Archit. Build. Eng., 5: 309-316. http://direct.bl.uk/bld/PlaceOrder.do?UIN=202555 893\&ETOC $=$ RN\& from $=$ searchengine

Krawinkler, H., 2000. State of art report on systems performance of moment resisting steel frames subject to earthquake ground shaking. SAC Report No. FEMA 355C, FEMA., Washington, DC. http://www.nehrp.gov/pdf/fema355c.pdf

Mazzoni, S. and F. Mackenna, 1999. OpenSees command language manual. http://opensees.berkeley.edu/OpenSees/manuals/use rmanual/OpenSeesCommandLanguageManual.pdf 